\title{
Sleep-disordered breathing and cardiovascular disease
}

\author{
J Amit Benjamin, K E Lewis
}

Prince Phillip Hospital, Llanelli, Wales, UK

Correspondence to: Dr J Amit Benjamin, Prince Phillip Hospital, Bryngwnmawr Dafen, Llanelli SA14 80F, Wales, UK;amitbenjal@hotmail.com

Received 4 July 2007 Accepted 20 November 2007

\section{ABSTRACT}

Sleep-disordered breathing (SDB) describes a group of disorders characterised by abnormalities in the frequency and/or depth of breathing while asleep. The most common type is the obstructive sleep apnoea/hypopnoea syndrome (OSAHS); it affects $2-4 \%$ of the adult population and is an independent risk factor for hypertension. Another type is central sleep apnoea (CSA), which includes Cheyne-Stokes respiration; it is most commonly seen in patients with congestive heart failure and other critical illnesses including cerebrovascular accidents. There is accumulating evidence that both these types of SDB are associated with cardiac failure, arrhythmias and coronary artery disease. Treatment of OSAHS with continuous positive airway pressure (CPAP) has lowered blood pressure, reduced the frequency and severity of some arrhythmias, and improved markers of endovascular inflammation. CPAP has had a mild positive effect on left ventricular function in chronic heart failure by treating co-existent SDB, but it has not improved mortality, possibly because it does not fully treat associated CSA. Clinicians need to be aware of the increasing associations of SDB, especially OSAHS, with cardiovascular dysfunction, as treatment of co-existent SDB will not only improve sleepiness, quality of life, and driving risk, but there is growing evidence that it may also improve cardiovascular risk itself, even in non-sleepy subjects.

Sleep-disordered breathing (SDB) was first described in the medical literature in $1936,{ }^{1}$ but has been described as far back as the 4th century BC, when Dionysius, tyrant of Heraclea, "lived in fear of suffocation from fat". ${ }^{2}$ Obstructive sleep apnoea/hypopnoea syndrome (OSAHS) is the most common type of SDB, affecting $\sim 4 \%$ of men and $2 \%$ of women aged $30-65$ years with a total population prevalence of $1-2 \%$, making it as least as common as type I diabetes. ${ }^{3}$

There are several different types of SDB, including:

- OSAHS

- Obesity hypoventilation syndrome

- Central sleep apnoea (CSA)

- Upper airway resistance syndrome

- Cheyne-Stokes respiration (CSR)

In this review, we concentrate on the association between the most prevalent type of SDB, namely OSAHS, and cardiac dysfunction, but, unlike in other reviews, we also describe some associations between CSA and CSR and cardiovascular disease.

OSAHS is defined as the coexistence of excessive daytime sleepiness with irregular breathing at night due to complete or partial closure of the upper airways. ${ }^{4}$ An apnoea is the absence of airflow at the nose and mouth for at least $10 \mathrm{~s}$ (due to complete airway occlusion), and a hypopnoea is a major reduction $(>50 \%)$ in airflow also for at least $10 \mathrm{~s}$ (partial airway narrowing)..$^{5}$ These are diagnosed during limited-channel sleep studies or polysomnography. The Apnoea/Hypopnoea Index (AHI) is the total number of apnoeas and/or hypopnoea events per hour of sleep. The $4 \%$ dip rate is the number of oxygen desaturations (from baseline) of at least 4\% associated with the apnoeas/hypopnoeas.

CSA has two distinct types. Hypercapnic CSA results from a chronically depressed respiratory drive associated with hypercapnia in wakefulness and sleep. ${ }^{6}$ The more common hypocapnic CSA is caused by a nocturnal pattern of breathing typified by regular crescendo-decrescendo oscillation of tidal volume, thought to be caused by dysfunction of central respiratory control. As the central drive to breathe fades, ventilation temporarily ceases before resuming again. Apnoeas and/or hypopnoeas can occur in CSA also. ${ }^{7}$ CSR refers to a type of normocapnic CSA followed by periodic hyperventilation, with both hypopnoeas and apnoeas. The presence of this respiratory pattern appears to be a particularly poor prognostic indicator of the presence of heart failure.

CSA occurs when there is cessation of inspiratory effort, but, in contrast with upper airway collapse, occurs sporadically and repetitively during sleep. Inspiratory efforts continue in obstructive sleep apnoea (OSA) but are ineffective because of upper airway obstruction. In OSAHS, apnoeas are terminated by recurrent arousals from sleep, which are needed to increase the tone of dilator muscles and open the upper airway; these recurrent microarousals cause sleep fragmentation, which often (but not always) causes the hallmark symptom of daytime tiredness and therefore the OSAHS.

Treatment of OSAHS with continuous positive airway pressure (CPAP) decreases the excess healthcare costs incurred by patients ${ }^{89}$ and reduces the risk of car accidents from an excess risk of 2-7 times greater than to equal to the background population. ${ }^{10}$ In the UK, CPAP is currently only recommended for treatment in symptomatic patients (ie, excessive daytime somnolence) and with an AHI $>15 / \mathrm{h}$ or a $4 \%$ oxygen dip rate of $>10 / \mathrm{h} .{ }^{411}$ Why would CPAP reduce the medical costs incurred by patients with OSAHS independently of reducing driving/occupational accidents? There is increasing evidence of an association between OSAHS and cardiovascular disease, and numerous reviews reflect this. ${ }^{12-16}$ OSAHS is certainly an independent risk factor for hypertension, ${ }^{17}{ }^{18}$ but, not only is there growing evidence 
that OSAHS is linked to other cardiovascular illnesses such as stroke, arrhythmias, coronary artery disease (CAD) and heart failure, but treating OSAHS may also improve these conditions. ${ }^{19-24}$

Given the widespread prevalence of heart disease and potential of undiagnosed sleep pathology, any associations would have implications for the current provision of sleep services. There is still much debate about whether SDB, in particular OSAHS, is an independent risk factor for cardiovascular dysfunction or a marker of another disease state. This review summarises the present evidence on cardiovascular risk and SDB, with particular emphasis on OSAHS and CSA. We suggest situations where it may be useful to screen for SDB and when treatment of co-existent SDB would be of benefit in patients with cardiovascular disease.

\section{OSAHS AND CARDIOVASCULAR DISEASE}

Many studies have alluded to a link between SDB and cardiovascular disease, but both (particularly OSAHS) may purely co-exist with type 2 diabetes, for example, ${ }^{25}$ therefore proving that SDB as an independent risk factor for cardiovascular disease is not straightforward. Previous cross-sectional and longitudinal population-based studies (Wisconsin Sleep Cohort, ${ }^{3}$ Pennsylvania Sleep Cohort ${ }^{26}{ }^{27}$ and the Cleveland Family Study $^{28}{ }^{29}$ ) confirmed only an association with OSAHS and multiple cardiovascular risk factors such as hypertension and diabetes. However, a large, prospective (11-year follow-up), multicentre, cohort study called the Sleep Heart Health Study ${ }^{30}$ showed excess cardiovascular mortality and morbidity in those with OSAHS after correction of results for known confounders. The Swedish 7-year cohort study of Peker et al ${ }^{31}$ showed a higher incidence of adverse cardiovascular events in untreated patients with OSAHS (who refused/or had poor CPAP compliance) than in both subjects without OSAHS and OSAHS patients with good CPAP compliance. ${ }^{31}$ Two more-recent studies confirmed excess cardiac events over a 10 -year period in patients with untreated severe OSAHS. ${ }^{32}{ }^{33}$ Recent data from more than
15000 subjects suggest that cardiovascular events are particularly prevalent in younger patients with OSAHS. ${ }^{34}$ However, these studies were not randomised controlled trials, as such long-term studies (needed to measure mortality) cannot be justified on ethical grounds because of the proven benefit of CPAP for hypertension, quality of life, and driving risk. Table 1 summarises the results of the main trials.

\section{OSAHS AND HYPERTENSION}

There is stronger evidence that OSAHS is an independent risk factor for hypertension than any other cardiovascular disease state and, moreover, that treatment with CPAP can reduce blood pressure. ${ }^{18}$ Previous work estimated that $\sim 40 \%$ of patients with OSAHS are hypertensive while awake ${ }^{35}$ and $40 \%$ of patients with refractory hypertension have OSAHS. ${ }^{36}$ More-recent cohort studies have suggested that OSAHS is present in up to $83 \%$ of patients with uncontrolled hypertension, despite taking three or more antihypertensive agents at optimum doses. ${ }^{37}$ Four large population-based studies have shown that OSAHS is an independent risk factor for hypertension. ${ }^{38-41}$ All four studies were able to adjust for age, body mass index (BMI) and sex. The Sleep Heart Health Study reported that the adjusted odds ratio for hypertension was 1.37 (95\% CI 1.03 to 1.83 ; $p$ for trend $=0.005)$, comparing subjects with an AHI $>30$ events per hour with those with an AHI $<1.5$ events per hour. ${ }^{39}$ The Wisconsin prospective sleep cohort of 709 subjects confirmed that those with "minimal", "mild-moderate" and "moderate-severe" SDB had adjusted odds ratios of developing hypertension of $1.42,2.03$ and 2.89, respectively, over the next 4 years, compared with subjects without SDB. This was after adjustment for baseline hypertension status, age, sex, BMI, waist and neck circumference, and weekly alcohol and cigarette use. ${ }^{41}$ Table 2 summarises some of these studies.

Two interventional (randomised controlled) studies showed a significant fall in blood pressure (BP) in patients receiving therapeutic CPAP (set at a pressure that abolished OSAHS) but no change in BP with "placebo" CPAP, set at sub-therapeutic

Table 1 Prevalence studies on cardiovascular disease and obstructive sleep apnoea/hypopnoea syndrome (OSAHS)

\begin{tabular}{|c|c|c|c|c|c|}
\hline Reference & $\begin{array}{l}\text { Study } \\
\text { type }\end{array}$ & $\begin{array}{l}\text { Type of } \\
\text { SDB }\end{array}$ & $\begin{array}{l}\text { Sample } \\
\text { size }\end{array}$ & Outcome & Comments \\
\hline Sahar et $a l^{30} 2001$ & CS & OSAHS & 1023 & $\begin{array}{l}\text { Relative odds }(95 \% \mathrm{CI}) \text { for: } \\
\text { OSAHS and heart failure } 2.38 \\
(1.22 \text { to } 4.62) \\
\text { OSAHS and stroke } 1.58 \text { (1.02 to } 2.46) \\
\text { OSAHS and coronary heart disease } \\
1.27(0.99 \text { to } 1.62) \text { (where no OSAHS } \\
(=\text { AHI of } 0-1.3) \text { to definite OSAHS } \\
(\mathrm{AHI}>11))\end{array}$ & $\begin{array}{l}\text { Representative population selection. } \\
\text { Multivariate analysis (as opposed to true matching) }\end{array}$ \\
\hline
\end{tabular}

Peker et $a l^{31} 2002 \quad C \quad$ OSAHS $182 \quad$ The incidence of at least one cardiovascular disease was observed in $36.7 \%$ of cases with OSA ( $4 \%$ dip rate $>30 / \mathrm{h})$ vs $6.6 \%$ subjects without $\mathrm{OSA}$ $(\mathrm{p}<0.001)$

Marin et $a l^{32} 2005 \quad C \quad$ OSAHS 1044

Doherty et $a l^{33} 2005$

OSAHS

Odds ratios $(95 \% \mathrm{CI})$ for cardiovascular
Multivariate analysis events in untreated severe OSAHS vs healthy participants:

- fatal events 2.87 (1.17 to 7.51)

- non-fatal events 3.17 (1.12 to 7.51)

Total cardiovascular events (ie, death and Average follow-up period of 7.5 years.

new cardiovascular disease combined). Matched for BMI.

More common in the untreated group

$(31 \%)$ than in the CPAP-treated group

$(18 \%)(p<0.05)$
All subjects (controls and OSAHS) free from cardiovascular disease/hypertension at baseline.

7-year follow-up

Control group matched for age and BMI.

Not matched for hypertension or diabetes.

"Untreated" CPAP group may be poor compliers with other treatments, also 10-year follow-up

Follow-up of OSAHS patients only. No "healthy controls". "Untreated" CPAP group may be poor compliers with other treatments 
Table 2 Prevalence studies on hypertension and obstructive sleep apnoea/hypopnoea syndrome (OSAHS)

\begin{tabular}{|c|c|c|c|c|}
\hline Study & Type & Subjects & Outcome & Comments \\
\hline $\begin{array}{l}\text { Hla et } a l^{42} 1994 \\
\text { (Wisconsin) }\end{array}$ & CS & 147 & $\begin{array}{l}\text { OR for hypertension above background population: } \\
\text { mild OSAHS, } 2.0 \\
\text { moderate/severe OSAHS, } 5.0\end{array}$ & Workplace population selection \\
\hline Grote et al ${ }^{40} 1999$ & $\mathrm{PC}$ & 1190 & $\begin{array}{l}\text { RR for hypertension increased with SDB severity. } \\
\text { OR for hypertension in severe OSAHS vs no OSAHS } \\
=4.15(95 \% \mathrm{Cl} 2.7 \text { to } 6.5)\end{array}$ & $\begin{array}{l}\text { Large numbers, confounders controlled for. } \\
\text { Statistics based on logistic regression, groups } \\
\text { differed in BMI/age }\end{array}$ \\
\hline Lavie et $a l^{38} 2000$ & CS & 2677 & $\begin{array}{l}\text { Multiple logistic regressions showed that each additional } \\
\text { apnoeic event per hour of sleep increased the odds of } \\
\text { hypertension by about } 1 \% \text {, and each } 10 \% \text { decrease in } \\
\text { nocturnal oxygen saturation increased the odds by } 13 \%\end{array}$ & $\begin{array}{l}\text { Subgroup analysis. OSAHS patients and controls } \\
\text { matched for age and BMI, but had higher BP. } \\
\text { No mention of sleepiness symptoms. } \\
\text { Multiple logistic regression }\end{array}$ \\
\hline Nieto et $a l^{\beta 9} 2000$ & $\mathrm{CS}$ & 6132 & $\begin{array}{l}\text { OR }(95 \% \mathrm{CI}) \text { for hypertension in severe OSAHS vs no } \\
\text { OSAHS: } \\
1.37(1.03 \text { to } 1.83), \mathrm{p}=0.005\end{array}$ & $\begin{array}{l}\text { Large numbers, confounders controlled for. } \\
\text { Stats based on logistic regression, groups differed in } \\
\text { BMI/age }\end{array}$ \\
\hline $\begin{array}{l}\text { Peppard et al }{ }^{41} 2000 \\
\text { (Wisconsin cohort) }\end{array}$ & CS and C & $\begin{array}{l}709 \text { (4-year } \\
\text { follow-up) and } \\
184 \text { (8-year } \\
\text { follow-up) }\end{array}$ & $\begin{array}{l}\text { Relative to } \mathrm{AHI} \text { of } 0 \text { at baseline, OR }(95 \% \mathrm{CI}) \text { for the } \\
\text { presence of hypertension at follow-up: } \\
1.42(1.13 \text { to } 1.78) \text { for no OSAHS } \\
2.03(1.29 \text { to } 3.17) \text { for mild OSAHS } \\
2.89(1.46 \text { to } 5.64) \text { for moderate OSAHS }\end{array}$ & $\begin{array}{l}\text { Large numbers, confounders controlled for. } \\
\text { Logistic regression, but groups differed in BMI/Age }\end{array}$ \\
\hline $\begin{array}{l}\text { Bixler et } a l^{43} 2000 \\
\text { (Pennsylvania) }\end{array}$ & CS & 1741 & $\begin{array}{l}\text { OR for OSAHS and hypertension: } \\
6.8 \text { for moderate to severe SDB } \\
2.3 \text { for mild SDB }\end{array}$ & $\begin{array}{l}\text { Representative population selection. } \\
\text { Not matched for BMI, diabetes, smoking, gender }\end{array}$ \\
\hline
\end{tabular}

AHI, Apnoea/Hypopnoea Index; BMI, body mass index; BP, blood pressure; C, cohort; CS, cross-sectional; PC, prospective cohort; SDB, sleep-disordered breathing.

pressure settings (table 3). ${ }^{35}{ }^{45}$ In one study, the improvement in BP correlated as strongly with improvement in sleepiness as with OSA severity. ${ }^{35}$ The study of Kaneko et al ${ }^{44}$ compared CPAP and optimal medical therapy with optimal therapy alone in OSA patients with heart failure. The fall in daytime systolic BP was $\sim 10 \mathrm{~mm} \mathrm{Hg}$ after 4 weeks of treatment in the CPAP group. All three studies not only suggest that OSAHS contributes to hypertension but that a fall of this magnitude in $\mathrm{BP}$ could potentially reduce the risk of a coronary heart disease event by $37 \%$ and the risk of a stroke event by $56 \% .{ }^{45}$

The pathogenic mechanism(s) linking SDB to hypertension are still not clear. Chronic hypoxia has been implicated, but a study comparing CPAP, sham CPAP and nocturnal oxygen showed no improvement in BP in the oxygen group, despite a significant improvement in mean saturations, a mean AHI (61 to 44) and reduction in time spent with saturations $<90 \%$ in the oxygen group. The group receiving therapeutic CPAP spent a similar amount of time with saturations $<90 \%$ to the oxygen group, but showed much greater improvements in mean AHI (66.1 to 3.4) and BP. This suggests that it is actual recurrent changes in saturation (or some other marker such as sleepiness) rather than mean saturations that are important in determining BP. ${ }^{46}$ An alternative theory whereby OSAHS may cause hypertension is overactivity of the sympathetic nervous system. Repetitive episodes of upper airways obstruction in OSA, resulting in intermittent hypoxia, and large swings in intrathoracic pressure (needed to overcome upper airways obstruction) have both been shown to trigger autonomic responses rather than hypoxia per $\mathrm{se}^{47}$ Markers of this sympathetic overactivity (eg, urinary norepinephrine concentrations) are raised in untreated OSAHS and can be reversed by CPAP therapy..$^{48}$ Even if the mechanisms are still being debated, the association between OSAHS and BP is now so clear that the US Joint National Committee on Hypertension puts OSAHS first on the list of the causes of secondary hypertension. ${ }^{49}$

\section{SDB AND HEART FAILURE}

SDB (in particular CSA) is common in heart failure, and these patients seem to have a worse prognosis than those without SDB.

Heart failure is becoming more common, affecting $1-3 \%$ of the UK population (rising to $10 \%$ in the elderly). ${ }^{50}$ In 2006 , Javaheri ${ }^{51}$ found that $49 \%$ of patients with a left ventricular (LV) ejection fraction of $<45 \%$ had severe SDB (defined as an AHI $>44 / h$ ) with $37 \%$ having CSA and $12 \%$ OSA, with or without daytime tiredness (OSAHS) (table 4). The Sleep Heart Health Study found that heart failure was 2.38 times more prevalent in "mild-moderate" OSA than in "mild-no" OSAH. ${ }^{30}$ Two previous studies suggested that SDB was present in $68 \%{ }^{52}$ and $72 \%{ }^{53}$ of patients with heart failure, but many of these patients were not optimally treated, in particular, $\beta$ blocker use only in the range $0-33 \%$. Wang and colleagues $^{54}$ followed 164

Table 3 Intervention studies on hypertension and obstructive sleep apnoea/hypopnoea syndrome

\begin{tabular}{|c|c|c|c|c|}
\hline Study & Type & Subjects & Outcome & Comments \\
\hline Pepperall et $\left.a\right|^{35} 2002$ & RCT & 95 & Mean BP fall $3.3 \mathrm{~mm} \mathrm{Hg}$ & $\begin{array}{l}\text { Sham CPAP. } \\
4 / 52 \text { of "Treatment". } \\
\text { Some subjects on antihypertensive drugs }\end{array}$ \\
\hline Kaneko et al ${ }^{44} 2003$ & $\mathrm{RCT}$ & 24 & $\begin{array}{l}\text { Reduction in daytime systolic BP from a mean (SE) } \\
\text { of } 126(6) \mathrm{mm} \mathrm{Hg} \text { to } 116(5) \mathrm{mm} \mathrm{Hg} \mathrm{(p=0.02)}\end{array}$ & $\begin{array}{l}\text { Both groups matched for BMI/AHI/sleepiness scores/ } \\
\text { ejection fraction at baseline. } \\
\text { Small numbers. } \\
\text { All had poor LV function. } \\
\text { No sham CPAP }\end{array}$ \\
\hline
\end{tabular}


Table 4 Prevalence studies of heart failure and sleep-disordered breathing (SDB) (both obstructive sleep apnoea (OSA) and central sleep apnoea (CSA))

\begin{tabular}{|c|c|c|c|c|}
\hline Reference & $\begin{array}{l}\text { Study } \\
\text { type }\end{array}$ & Subjects & Outcome & Comments \\
\hline Sinn et $a /^{53} 1999$ & $\mathrm{RCA}$ & 450 & $\begin{array}{l}\text { In a cohort of patients with heart failure, } 70 \% \text { of } \\
\text { subjects had SDB: } \\
-32 \% \text { had predominantly CSA } \\
\quad 38 \% \text { had predominantly OSAHS }\end{array}$ & $\begin{array}{l}\text { Patients recruited from referrals to sleep clinic, ie, } \\
\text { selected for sleepiness. } \\
\text { Not all patients had an ejection fraction }<45 \% \text {; initial } \\
\text { diagnosis made clinically }\end{array}$ \\
\hline Sahar et $a l^{30} 2001$ & CS & 1023 & $\begin{array}{l}\text { Relative odds ( } 95 \% \mathrm{CI}) \text { for OSAHS vs no OSAHS in } \\
\text { heart failure patients, } 2.38(1.22 \text { to } 4.62)\end{array}$ & $\begin{array}{l}\text { Screening of over } 6000 \text { subjects from general } \\
\text { population }\end{array}$ \\
\hline Ferrier et $\left.a\right|^{52} 2005$ & PC & 53 & $\begin{array}{l}\text { SDB }(A H I>10) \text { demonstrated in } 36 \text { of } 53 \text { patients } \\
\text { with heart failure }(68 \%) \text {. } \\
\text { OSA }(53 \%) \text { and CSA }(15 \%)\end{array}$ & $\begin{array}{l}\text { Unselected patients with stable heart failure. } \\
\text { High proportion of local ethnic subjects (Maori) and only } \\
\text { men studied }\end{array}$ \\
\hline Javaheri $^{5^{1}} 2006$ & $\mathrm{PC}$ & 100 & $\begin{array}{l}\text { Severe SDB seen in } 49 \% \text { of patients who had a } \\
\text { LVEF of }<45 \% \text {. } \\
37 \% \text { had CSA and } 12 \% \text { had OSA. } \\
\text { Most were not sleepy }\end{array}$ & $\begin{array}{l}\text { Patients recruited from cardiology clinics and primary } \\
\text { care }\end{array}$ \\
\hline Wang et $a f^{54} 2007$ & PLC & 218 & $\begin{array}{l}\text { In a cohort of patients with heart failure, } 46 \% \text { had } \\
\text { definite SDB } \\
\text { ( } 45 \text { subjects with CSA and } 56 \text { with OSA): } \\
\text { - } 21 \% \text { had predominantly CSA } \\
\text { - } 25 \% \text { had predominantly OSA }\end{array}$ & $\begin{array}{l}\text { Death rate higher in the untreated SDB group, but these } \\
\text { consisted of those who were unable/unwilling to use } \\
\text { CPAP which may be a marker of poor compliance with } \\
\text { other health behaviours. } \\
\text { A mean 2.9-year follow-up }\end{array}$ \\
\hline
\end{tabular}

AHI, Apnoea/Hypopnoea Index; CPAP, continuous positive airway pressure; CS, cross-sectional; LVEF, left ventricular ejection fraction; OSAHS, obstructive sleep apnoea/hypopnoea syndrome; PC, prospective cohort; PLC, prospective longitudinal cohort; RCA, retrospective cohort analysis.

patients with heart failure over a mean of 3 years and found the death rate was significantly higher in the 37 untreated patients $(\mathrm{AHI}>15)$ than in the 113 patients with mild or no SDB (AHI $<25 / \mathrm{h}$ ), even after controlling for confounding factors (age, LV ejection fraction and New York Heart Association functional class), with 8.7 vs 4.2 deaths per 100 patient-years ( $p=0.029$ ).

One important aspect of SDB in heart failure is the occurrence of CSA (including CSR), which is estimated to occur in $40-63 \%$ of patients ${ }^{51}{ }^{53}$ and, when present, is associated with a particularly poor prognosis. ${ }^{55}$ The pathophysiology (including effect on LV volume and the sympathetic nervous system) of CSA is important but beyond the remit of this paper; it has been described elsewhere. ${ }^{56-58}$ OSAs can adversely affect cardiac function through large intrathoracic pressure swings occurring during respiratory efforts, increasing venous return and therefore ventricular afterload. Sympathetic activation, secondary to hypoxia and arousal, further increases BP and therefore myocardial oxygen consumption at the end of apnoeas. These adverse effects on LV function can be at least partially reversed by CPAP. ${ }^{59}$ CPAP is now recommended in the acute treatment of cardiogenic pulmonary oedema irrespective of the presence of SDB; it works by improving intrathoracic fluid dynamics. ${ }^{61}$ Standard treatments for symptomatic SDB associated with chronic heart failure are oxygen (for CSA) and CPAP (for OSA) in their own right, but evidence for their use in improving longer-term cardiovascular outcomes in non-sleepy patients is still equivocal. Nocturnal oxygen has been found to improve the AHI and some sympathetic parameters of patients with OSAHS, ${ }^{62}{ }^{63}$ but it has had no effect on quality of life $^{64}$ or LV ejection fraction. ${ }^{65}$ (Both studies were short term and so could not look at mortality.) The results from trials with CPAP in chronic heart failure have been only slightly more promising, but by no means conclusive (table 5). Early studies showed an improvement in LV ejection fraction of up to $7 \%$, but they all had small numbers in both the CPAP and conventional treatment arms, and many patients were not prescribed drugs (especially $\beta$ blockers) according to current heart failure guidelines. ${ }^{66-68}$ The largest trial so far to address sample size, adequate duration and maximising medical treatment is the multicentre CANPAP trial. Here, over 400 patients with congestive cardiac failure and SDB were randomised to best medical care or CPAP in addition to best medical care. The improvement in LV ejection fraction in the CPAP arm was only $2.2 \%$, but there was a statistically significant improvement in the 6 min walk test by $20 \mathrm{~m}$, compared with a mean deterioration of $0.8 \mathrm{~m}$ in the optimal treatment group, over the same time period. The study was stopped early because of lower than expected enrolment rate, a falling primary event rate (because of advances in management of congestive cardiac failure), and concerns after increased mortality in the CPAP arm at 3 months. However, the early divergence in survival curves reversed after 18 months to favour the CPAP group, but the overall mortality was no different after 18 months. When assessing differences in ejection fraction, it is important to note that $70 \%$ of subjects in this trial were prescribed $\beta$ blockers (compared with $20 \%$ or less in previous studies) which may render some of the beneficial effects of CPAP on sympathetic activation redundant. ${ }^{69}$ Others suggest that, although the prevalence of CSA remains high in patients with LV dysfunction, there was no difference in prevalence in those prescribed $\beta$ blockers compared with those not using $\beta$ blockers, but this was a small study $(\mathrm{n}=14) .^{70}$

In summary, the current data do not support routine use of CPAP in chronic stable congestive cardiac failure unless there is co-existent OSAHS. Bi-level pressure support using newer devices that may more effectively treat both CSA and OSA (which often co-exist) are being evaluated (K E Lewis and $M$ Arzt, personal communication).

\section{OSAHS AND ARRHYTHMIAS}

Cyclic variation in heart rate is typical in SDB. Apnoea and hypoxaemia-induced bradycardia is often followed by tachycardia during the post-apnoeic hyperventilation. This section reviews the current evidence for a strong association between arrhythmias and SDB and shows how treatment of the SDB can potentially abolish the arrhythmia.

The association between OSAHS and arrhythmias was first documented over 30 years ago. In the study of Guilleminault et $a l,{ }^{71}$ of 400 patients with OSAHS, 48\% had documented cardiac arrhythmias, including sustained ventricular tachycardia in $2 \%$, sinus arrest in $11 \%$, second-degree atrioventricular block in $8 \%$, and frequent premature ventricular contractions in $19 \%$. 
Table 5 Summary of the treatment of sleep-disordered breathing (SDB) in subjects with heart failure

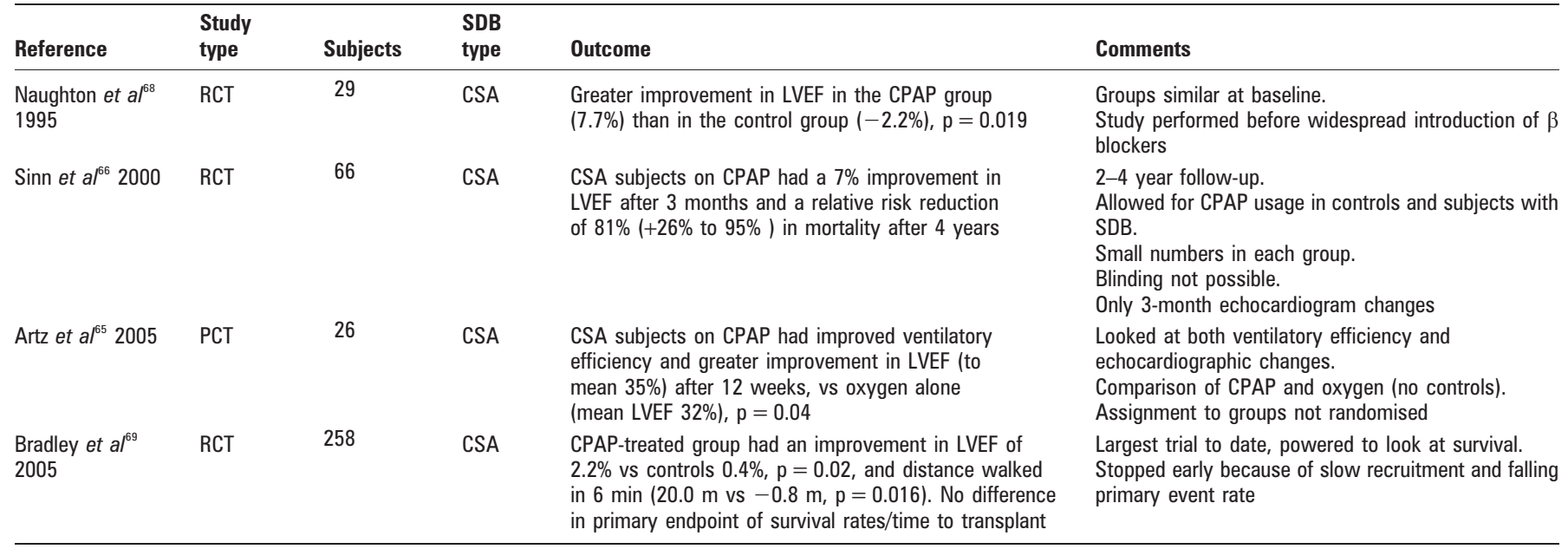

CPAP, continuous positive airway pressure; CS, cross-sectional; CSA, central sleep apnoea; LVEF, left ventricular ejection fraction; OSAHS, obstructive sleep apnoea/hypopnoea syndrome; PC, prospective cohort; PCT, prospective controlled trial; PLC, prospective longitudinal cohort; RCT, randomised controlled trial.

Tracheostomy in 50 patients cured the OSAHS and abolished these arrhythmias. This study only looked at patients with OSAHS, and 246 patients were already prescribed amphetamine for daytime sleepiness, which is pro-arrhythmogenic. Other weaknesses of this study are that no distinction is made between patients with pre-existing cardiac disease. The 1995 study of Beckers et $a l^{72}$ revealed that $7 \%$ of 239 patients with OSAHS had significant bradyarrhythmias, and, of these 17 patients, only one continued to experience bradyarrhythmias after CPAP therapy. Most of these patients had established or newly diagnosed cardiac abnormalities (hypertension, congestive cardiac failure, pulmonary hypertension), so any independent effect of OSAHS is difficult to establish. In a much smaller study, Tilkian et al ${ }^{73}$ found bradyarrhythmias in five out of 15 patients with OSAHS. In most of these prevalence studies, arrhythmias were diagnosed in patients with OSAHS using simple 24-48 h cardiac Holter monitoring. However, in an elegant study (albeit again with small numbers), Simantirakis et $a l^{74}$ inserted loop recording devices in 23 patients with OSAHS in whom other cardiac and pulmonary disease was first excluded with exercise tests, invasive electrophysiological studies, echocardiography, and lung function tests, and diabetes was also excluded. Over 2 months of continuous recording, 48\% had significant rhythm disturbances, mostly occurring at night. They also noted a near-total failure of $48 \mathrm{~h}$ Holter monitoring to detect events during the same time period. On an intention-totreat basis, there was a significant improvement in rhythm disturbances within 8 weeks, and all rhythm disturbances were abolished after 6 months of CPAP therapy, although the background prevalence of undiagnosed arrhythmias was not reported and there was no control group not receiving CPAP in the arrhythmia group, nor a description of CPAP usage.

Atrial fibrillation (AF) is another arrhythmia widely reported to be associated with OSAHS. A subgroup analysis of the Sleep Heart Health Study revealed a fourfold increase (odds ratio 4.02; $95 \%$ CI 1.03 to 15.74 ) in the prevalence of AF in subjects with an AHI >30 compared with patients with no SDB matched for age, sex, ethnicity and BMI. ${ }^{75}$ Gami et al ${ }^{76}$ used the Berlin Sleep Questionnaire to estimate the prevalence of OSAHS in 468 cardiology patients. They found that AF occurred in $49 \%$ of patients with OSAHS compared with $32 \%$ of general cardiology outpatients deemed at low risk of OSAHS but matched for age, gender and comorbidity $(p=0.0004)$. Sleep studies were only performed in 44 patients (to validate the questionnaire, and the AF group had a larger neck size, an independent predictor of OSAHS). A smaller Finnish study from the same year, using objective sleep studies, disagreed and actually found no difference in the prevalence of OSAHS in 59 patients with lone AF compared with 56 controls matched for age, gender and cardiovascular morbidity. ${ }^{77}$ Increased rates of recurrence of AF (after cardioversion) have been shown in inadequately treated patients with OSAHS compared with non-OSAHS and welltreated OSAHS patients. ${ }^{78}$ The bradyarrhythmias in patients with OSAHS possibly reflect the reflex parasympathetic activity evoked by apnoeas, but AF may be caused by increased sympathetic activity after apnoeas or increased atrial size seen in patients with OSAHS. ${ }^{47}$ Even if the causal mechanisms are not yet clear, the overlap between arrhythmias and OSAHS should at least prompt clinicians to ask about OSAHS symptoms in patients with cardiac rhythm disturbances.

\section{OSAHS AND CORONARY ARTERY DISEASE}

Patients with SDB have a high prevalence of CAD, and patients with CAD have a high prevalence of SDB.

The case-control study of Peker et a ${ }^{79}$ looked at 62 patients with $\mathrm{CAD}$ and 62 patients without $\mathrm{CAD}$, matched for age, sex, BMI, hypertension, hypercholesterolaemia, diabetes mellitus and current smoking. In a multiple logistic regression model, the presence of OSAHS remained independently associated with $\mathrm{CAD}$ (odds ratio 3.1vs 9.8 for current smoking and 4.2 for diabetes mellitus). The large Swedish cohort studies of Mooe et $a^{80} 81$ also suggested that OSAHS was much more prevalent in the 142 patients with established CAD (angiography) than in the 50 controls (with normal angiography). This was true for both men $^{80}$ and women, ${ }^{81}$ even after adjustment for confounders.

Cross-sectional results from the population-based Sleep Heart Health Study ${ }^{30}$ showed that, in patients with SDB, the multivariable-adjusted relative odds $(95 \% \mathrm{CI})$ with self-reported coronary heart disease was a more modest 1.27 (0.99 to 1.62) (comparing upper with lower quartiles of severity of SDB).

Sudden cardiac death is more common in patients with OSAHS, after adjustment for confounders. Gami et al looked at 112 subjects who had undergone polysomnography over a 5year period; sudden death from cardiac causes (between the hours of midnight and $6 \mathrm{am}$ ) occurred in $46 \%$ of patients with 


\section{Main messages}

- Sleep-disordered breathing (SDB) consists of obstructive sleep apnoea/hypopnoea syndrome (OSAHS) and central sleep apnoea (CSA).

- OSAHS in particular appears to be an independent risk factor for cardiovascular disease and should be considered in patients with cardiovascular dysfunction, especially hypertension, as treatment with continuous positive airway pressure (CPAP) can lower blood pressure by as much as $10 \mathrm{~mm} \mathrm{Hg}$ in symptomatic patients. A sleep history and referral would be useful in the workup of hypertensive patients, especially those with refractory hypertension.

- SDB (especially CSA) is common in patients with heart failure. These patients tend not to have the typical excessive daytime sleepiness of OSAHS. At present, only patients with OSAHS who have heart failure are recommended for CPAP therapy.

- The presence of OSAHS should be considered in patients with arrhythmias (especially atrial fibrillation or bradyarrhythmias), particularly those who are obese or hypertensive.

- Future research will be directed to improving cardiovascular outcomes by treating SDB (including CSA) more effectively in non-sleepy patients. Larger studies will be performed to see if improvements in blood pressure and endovascular outcome translate to mortality benefits in all forms of SDB.

OSAHS compared with $21 \%$ of tired people with negative sleep studies $(p=0.01)$ and $16 \%$ of the general population $(p<0.001)$. There was no excess of sudden cardiac death in the patients with OSAHS during waking hours. Mooe et a $l^{83}$ followed 408 patients with verified CAD (on angiogram) for 5 years after they all had sleep studies. Subjects with SDB had an adjusted risk ratio of 1.70 ( $95 \%$ CI 1.2 to $2.5, \mathrm{p}=0.008$ ) for the composite endpoint of death, cerebrovascular events and myocardial infarction. The authors concluded that SDB in subjects with known $\mathrm{CAD}$ is associated with a worse long-term prognosis.

Peker et a ${ }^{84}$ followed 105 patients with OSAHS who were free from $\mathrm{CAD}$ at baseline for 7 years. CAD occurred in $16 \%$ compared with only $5 \%$ of 203 snorers without OSAHS free from $\mathrm{CAD}$ at baseline. This study also suggested a protective effect of CPAP within the OSAHS group: CAD developed in $25 \%$ of the 65 incompletely treated patients, but in only one (4\%) of the 26 well-treated patients. ${ }^{84}$ Such studies are not prospective randomised trials and are weakened by the possibility that poor acceptance/compliance with CPAP may be a marker for poor compliance with lifestyle modifications and other treatments shown to reduce cardiovascular risk. A smaller but much longer (10 year) prospective study showed equal cardiac death rates (four of 25) in people with established CAD whether they had OSAHS or not, but groups were not matched for age, BMI, hypertension, etc. ${ }^{85}$ OSAHS can cause $\mathrm{CAD}$ indirectly via hypertension or directly by generation of free radicals, activating endovascular inflammation during the recurrent episodes of deoxygenation-oxygenation. ${ }^{12}$

To summarise, there is an association between OSAHS and anatomical CAD, but the clinical significance and effect of CPAP treatment remain unclear.

\section{CONCLUSIONS}

Many cardiovascular diseases are independently associated with SDB. Early cross- sectional and observational studies suggested links, but were open to selection and reporting bias and may not

\section{Key references for further reading}

1. McNicholas WT, Bonsigore MR. Sleep apnoea as an independent risk factor for cardiovascular disease: current evidence, basic mechanisms and research priorities. Eur Respir J 2007;29:156-78.

2. Phillips B. Sleep-disordered breathing and cardiovascular disease. Sleep Med Rev 2005;9:131-40.

3. Parish JM, Somers VK. Obstructive sleep apnea and cardiovascular disease. Mayo Clin Proc 2004;79:1036-46.

4. Quan SF, Gersh BJ. Cardiovascular consequences of sleepdisordered breathing: past, present and future: report of a workshop from the National Center on Sleep Disorders Research and the National Heart, Lung, and Blood Institute. Circulation 2004;109:951-7.

5. Arzt M, Bradley TD. Treatment of sleep apnea in heart failure. Am J Respir Crit Care Med 2006;173:1300-8.

have adequately controlled for important confounders such as obesity and hypertension. However, well-designed randomised controlled (intervention) trials have now established that OSAHS is an independent and treatable risk factor at least for hypertension. Further prevalence studies and now interventional trials suggest that $\mathrm{SDB}$, and OSAHS in particular, may cause and exacerbate other cardiovascular dysfunction, particularly cardiac failure, arrhythmias and possibly CAD.

The mechanism(s) behind these associations are biologically plausible and, together with the direction of cause-and-effect, are still being elucidated.

Awareness of the association of cardiovascular disease and SDB will prompt the general practitioner to look for both illnesses when presented with one of them. There is no doubt that CPAP and other treatments for SDB will make symptomatic patients who happen to have a cardiac disease feel better. It may be that CPAP will be used to improve cardiac outcomes in their own right, and randomised controlled trials of CPAP in patients with cardiovascular risk and OSAHS but who are not sleepy are being designed.

\section{TRUE (T)/FALSE (F) QUESTIONS (ANSWERS AFTER THE REFERENCES)}

(A) OSAHS can be diagnosed from a history of irregular breathing at night.

(B) OSAHS is an established independent risk factor for hypertension as well as heart failure, stroke, arrythmias and coronary artery disease.

(C) Treatment of OSAHS with CPAP can cause a drop in blood pressure.

(D) All patients with heart failure and sleep disordered breathing should be treated with CPAP.

(E) There is growing evidence linking OSAHS and arrythmias.

Competing interests: None.

\section{REFERENCES}

1. Spitz A. Das klinische syndrome: Narcolepsy mit Fettsucht und Polyglobulien seinem Beziehungen zum morbus Cushing. Deutsch Arch Klin Med 1937;181:286.

2. Kryger MH. Sleep apnea. From the needles of Dionysius to continuous positive airway pressure. Arch Intern Med 1983;143:2301-3.

3. Young T, Palta M, Dempsey J, et al. The occurrence of sleep-disordered breathing among middle-aged adults. N Engl J Med 1993;328:1230-5.

4. Scottish Intercollegiate Guidelines Network. Guideline number 73. June 2003.www.sign.ac.uk (accessed 6 Dec 2007). 
5. Sleep-related breathing disorders in adults: recommendations for syndrome definition and measurement techniques in clinical research. The Report of an American Academy of Sleep Medicine Task Force. Sleep 1999;22:667-89.

6. Krachman S, Criner GJ. Hypoventilation syndromes. Clin Chest Med 1998;19:139_ 55 .

7. Kohnlein T, Welte T, Tan LB, et al. Central sleep apnoea syndrome in patients with chronic heart disease: a critical review of the current literature. Thorax 2002:57:54754.

8. Wittman V, Rodenstein DO. Health care costs and the sleep apnea syndrome. Sleep Med Rev 2004:8:269-79.

9. Pelletier-Fleury N, Meslier N, Gagnadoux F, et al. Economic arguments for the immediate management of moderate-to-severe obstructive sleep apnoea syndrome. Eur Respir J 2004;23:53-60.

10. Ayas NT, Fitzgerald JM, Fleetham JA, et al. Cost-effectiveness of continuous positive airway pressure therapy for moderate to severe obstructive sleep apnea/ hypopnea. Arch Intern Med 2006;166:977-84.

11. National Health and Medical Research Council. Effectiveness of nasal continuous positive airway pressure (nCPAP) in obstructive sleep apnoea in adults. Canberra: The Council, 2000.http://www.nhmrc.gov.au (accessed 6 Dec 2007).

12. McNicholas WT, Bonsigore MR. Sleep apnoea as an independent risk factor for cardiovascular disease: current evidence, basic mechanisms and research priorities. Eur Respir J 2007;29:156-78.

13. Phillips B. Sleep-disordered breathing and cardiovascular disease. Sleep Med Rev 2005:9:131-40.

14. Parish JM. Somers VK. Obstructive sleep apnea and cardiovascular disease. Mayo Clin Proc 2004:79:1036-46.

15. Quan SF. Gersh BJ. Cardiovascular consequences of sleep-disordered breathing past, present and future: report of a workshop from the National Center on Sleep Disorders Research and the National Heart, Lung, and Blood Institute. Circulation 2004; 109:951-7.

16. Shamsuzzaman AS. Gersh BJ. Somers VK. Obstructive sleep apnea: implications for cardiac and vascular disease. JAMA 2003;290:1906-14

17. Young T, Peppard P, Palta M, et al. Population-based study of sleep-disordered breathing as a risk factor for hypertension. Arch Intern Med 1997:157:1746-52.

18. Robinson GV, Stradling JR, Davies RJ. Sleep. 6: Obstructive sleep apnoea/ hypopnoea syndrome and hypertension. Thorax 2004;59:1089-94.

19. Arzt M, Bradley TD. Treatment of sleep apnea in heart failure. Am J Respir Crit Care Med 2006;173:1300-8.

20. Yaggi H, Mohsenin V. Obstructive sleep apnoea and stroke. Lancet Neurol 2004;3:333-42.

21. Arzt M, Young T, Finn L, et al. Association of sleep disordered breathing and the occurrence of stroke. Am J Respir Crit Care Med 2005:172:1447-51.

22. Guilleminault C, Connolly SJ, Winkle RA. Cardiac arrhythmia and conduction disturbances during sleep in 400 patients with sleep apnoea syndrome. Am J Cardiol 1983:52:490-4.

23. Peker Y, Kraiczi H, Hedner J, et al. An independent association between obstructive sleep apnoea and coronary artery disease. Eur Respir J 1999:14:179-84.

24. Wang H, Parker JD, Newton GE, et al. Influence of obstructive sleep apnea on mortality in patients with heart failure. J Am Coll Cardiol 2007;49:1625-31.

25. West SD, Nicoll DJ, Stradling JR. Prevalence of obstructive sleep apnoea in men with type 2 diabetes. Thorax 2006;61:945-50.

26. Bixler E0, Vgontzas AN, Ten Have T, et al. Effects of age on sleep apnea in men. I. Prevalence and severity. Am J Respir Crit Care Med 1998:157:144-8.

27. Bixler E0, Vgontzas AN, Lin HM, et al. Prevalence of sleep-disordered breathing in women: effects of gender. Am J Respir Crit Care Med 2001;163:608-13.

28. Redline S, Tishler PV, Hans MG, et al. Racial differences in sleep-disordered breathing in African-Americans and Caucasians. Am J Respir Crit Care Med 1997; 155:186-92.

29. Redline S, Tishler PV, Schluchter M, et al. Risk factors for sleep-disordered breathing in children. Associations with obesity, race, and respiratory problems. Am J Respir Crit Care Med 1999;159:1527-32.

30. Shahar E, Whitney CW, Redline S, et al. Sleep-disordered breathing and cardiovascular disease. Cross-sectional results of the Sleep Heart Health Study. Am J Respir Crit Care Med 2001:163:19-25.

31. Peker Y, Hedner J, Norum J, et al. Increased incidence of cardiovascular disease in middle-aged men with obstructive sleep apnea: a 7-year follow-up. Am J Respir Crit Care Med 2002;166:159-65.

32. Marin JM, Carrizo SJ, Vicente E, et al. Long-term cardiovascular outcomes in men with obstructive sleep apnoea-hypopnoea with or without treatment with continuous positive airway pressure: an observational study. Lancet 2005;365:1046-53.

33. Doherty LS, Kiely JL, Swan V, et al. Long-term effects of nasal continuous positive airway pressure therapy on cardiovascular outcomes in sleep apnea syndrome. Chest 2005; 127:2076-84.

34. Lavie $\mathbf{P}$, Lavie L, Herer P. All-cause mortality in males with sleep apnoea syndrome: declining mortality rates with age. Eur Respir J 2005:25:514-52.

35. Pepperell JCT, Ramdassingh-Dow S, Crosthwaite N, et al. Ambulatory blood pressure following therapeutic and sub-therapeutic nasal continuous positive airway pressure for obstructive sleep apnoea: a randomised prospective parallel trial. Lancet 2002;359:204-10.

36. Rauscher H, Popp W, Zwick H. Systemic hypertension in snorers with and without sleep apnea. Chest 1992;102:367-71.

37. Logan AG, Perlikowski SM, Mente A, et al. High prevalence of unrecognized sleep apnoea in drug-resistant hypertension. J Hypertens 2001:19:2271-7.
38. Lavie $\mathbf{P}$, Herer P and Hoffstein V. Obstructive sleep apnoea syndrome as a risk factor for hypertension: population study. BMJ 2000;320:479-82.

39. Nieto FJ, Young TB, Lind BK, et al. Association of sleep-disordered breathing, sleep apnea, and hypertension in a large community-based study. JAMA 2000;283:182936.

40. Grote L, Ploch T, Heitmann J, et al. Sleep-related breathing disorder is an independent risk factor for systemic hypertension. Am J Respir Crit Care Med 1999;160:1875-82

41. Peppard PE, Young T, Palta M, et al. Prospective study of the association between sleep-disordered breathing and hypertension. N Engl J Med 2000:342:1378-84.

42. Hla KM, Young TB, Bidwell T, et al. Sleep apnea and hypertension. A populationbased study. Ann Intern Med 1994:120:382-8.

43. Bixler E0, Vgontzas AN, Lin HM, et al. Association of hypertension and sleepdisordered breathing. Arch Intern Med 2000;160:2289-95.

44. Kaneko Y, Floras JS, Usui, et al. Cardiovascular effects of continuous positive airway pressure in patients with heart failure and obstructive sleep apnea. N Engl J Med 2003;348:1233-41

45. Becker HF, Jerrentrup A, Ploch $\mathrm{T}$, et al. Effect of nasal continuous positive airway pressure treatment on blood pressure in patients with obstructive sleep apnea. Circulation 2003;107:68-78

46. Norman D, Loredo JS, Nelesen RA, et al. Effects of continuous positive airway pressure versus supplemental oxygen on 24-hour ambulatory blood pressure. Hypertension 2006:47:840-5.

47. Somers VK, Dyken ME, Clary MP, et al. Sympathetic neural mechanisms in obstructive sleep apnea. J Clin Invest 1995;96:1897-904

48. Ziegler MG, Mills PJ, Loredo JS, et al. Effect of continuous positive airway pressure and placebo treatment on sympathetic nervous activity in patients with obstructive sleep apnea. Chest 2001;120:887-93.

49. Chobanian AV, Bakris GL, Black HR, and National Heart Lung and Blood Institute Joint National Committee on Prevention, Detection, Evaluation, and Treatment of High Blood Pressure: National High Blood Pressure Education Program Coordinating Committee, The seventh report of the joint national committee on prevention, detection, evaluation, and treatment of high blood pressure: the JNC 7 report. JAMA 2003:289:2560-72

50. McMurray JJV, Stewart S. The burden of heart failure. Eur Heart J Supp 2002;4(Suppl D):D50-8.

51. Javaheri S. Sleep disorders in systolic heart failure: a prospective study of 100 male patients. The final report. Int J Cardiol 2006;106:21-8.

52. Ferrier $\mathbf{K}$, Campbell, Yee B, et al. Sleep-disordered breathing occurs frequently in stable outpatients with congestive heart failure. Chest 2005;128:2116-22.

53. Sin DD, Fitzgerald F, Parker JD, et al. Risk factors for central and obstructive sleep apnea in 450 men and women with congestive heart failure. Am J Respir Crit Care Med 1999;160:1101-6.

54. Wang H, Parker JD, Newton G, et al. Influence of obstructive sleep apnea on mortality in patients with heart failure. J Am Coll Cardiol 2007:49:1632-3.

55. Bradley T D, Floras J. Sleep apnea and heart failure. Part II. Central sleep apnea. Circulation 2003:107:1822.

56. Tkacova $\mathbf{R}$, Hall MJ, Liu PP, et al. Left ventricular volume in patients with heart failure and Cheyne-Stokes respiration during sleep. Am J Respir Crit Care Med 1997:156:1549-555.

57. Spaak J, Egri ZJ, Kubo T, et al. Muscle sympathetic nerve activity during wakefulness in heart failure patients with and without sleep apnea. Hypertension 2005:46:1327-32.

58. Leung RS, Floras JS, Lorenzi-Filho G, et al. Influence of Cheyne-Stokes respiration on cardiovascular oscillations in heart failure. Am J Respir Crit Care Med 2003;167:1534-9.

59. Hall MJ, Ando SI, Floras JS, et al. Magnitude and time course of hemodynamic responses to Mueller maneuvers in patients with congestive heart failure. J App / Physiol 1998;85:1476-84.

60. Tkacova R, Rankin F, Fitzgerald FS, et al. Effects of continuous positive airway pressure on obstructive sleep apnea and left ventricular afterload in patients with heart failure. Circulation 1998;98:2269-75

61. Nieminen MS, Böhm M, Cowie MR, et al. Executive summary of the guidelines on the diagnosis and treatment of acute heart failure: the Task Force on Acute Heart Failure of the European Society of Cardiology. Eur Heart J 2005;26:384-416.

62. Krachman SL, D'Alonzo GE, Berger TJ, et al. Comparison of oxygen therapy with nasal continuous positive airway pressure on Cheyne-Stokes respiration during sleep in congestive heart failure. Chest 1999;116:1550-7.

63. Staniforth AD, Kinnear WJ, Starling R, et al. Effect of oxygen on sleep quality, cognitive function and sympathetic activity in patients with chronic heart failure and Cheyne-Stokes respiration. Eur Heart J 1998;19:922-8.

64. Andreas S, Clemens C, Sandholzer H, et al. Improvement of exercise capacity with treatment of Cheyne-Stokes respiration in patients with congestive heart failure. J Am Coll Cardiol 1996;27:1486-90.

65. Arzt M, Schulz M, Wensel R, et al. Nocturnal continuous positive airway pressure improves ventilatory efficiency during exercise in patients with chronic heart failure. Chest 2005:127:794-802.

66. Sin DD, Logan AG, Fitzgerald FS, et al. Effects of continuous positive airway pressure on cardiovascular outcomes in heart failure patients with and without Cheyne-Stokes respiration. Circulation 2000;102:61-6.

67. Arzt M, Schulz M, Wensel R, et al. Nocturnal continuous positive airway pressure improves ventilatory efficiency during exercise in patients with chronic heart failure. Chest 2005:127:794-802. 
68. Naughton MT, Liu PP, Bernard DC, et al. Treatment of congestive heart failure and Cheyne-Stokes respiration during sleep by continuous positive airway pressure. Am J Respir Crit Care Med 1995;151:92-7.

69. Bradley TD, Logan AG, Kimoff RJ, et al. Continuous positive airway pressure for central sleep apnea and heart failure. N Engl J Med 2005;353:2025-33.

70. Bayle JY, Grouet A, Gueyffier F, et al. The central sleep apnoea syndrome is frequent in the left ventrcle systolic dysfunction treated with betablockers. Am J Respir Crit Care Med 2007;175:A577.

71. Guilleminault C, Connolly SJ, Winkle RA. Cardiac arrhythmias and conduction disturbances during sleep in 400 patients with sleep apnea syndrome. Am J Cardiol 1983;22:490-4

72. Becker $\mathbf{H}$, Brandenburg U, Peter $\mathbf{J H}$, et al. Reversal of sinus arrest and atrioventricular conduction block in patients with sleep apnea during nasal continuous positive airway pressure. Am J Respir Crit Care Med 1995;151:215-18.

73. Tilkian AG, Guilleminault C, Schroeder JS, et al. Sleep induced apnoea syndrome: prevalence of cardiac arrhythmias and their reversal after tracheostomy. Am J Med 1977:63:348-58.

74. Simantirakis N, Schiza SI, Marketou ME, et al. Severe bradyarrhythmias in patients with sleep apnoea: the effect of continuous positive airway pressure treatment. A long-term evaluation using and insertable loop recorder. Eur Heart J 2004:25:1070-6.

75. Mehra R, Benjamin EJ, Shahar E, et al. Association of nocturnal arrhythmias with sleep-disordered breathing: the Sleep Heart Health Study. Am J Respir Crit Care Med 2006:173:910-16.

76. Gami AS, Pressman G, Caples SM, et al. Association of atrial fibrillation and obstructive sleep apnea. Circulation 2004:110:364-7.

77. Porthan KM, Melin JH, Kupila JT, et al. Prevalence of sleep apnea syndrome in lone atrial fibrillation: a case-control study. Chest 2004;125:879-85.
78. Kanagala R, Murali NS, Friedman PA, et al. Obstructive sleep apnea and the recurrence of atrial fibrillation. Circulation 2003:107:2589-94.

79. Peker Y, Kraiczi H, Hedner J, et al. An independent association between obstructive sleep apnoea and coronary artery disease. Eur Respir J 1999:14:179-84.

80. Mooe T, Rabben T, Wiklund U, et al. Sleep-disordered breathing in men with coronary artery disease. Chest 1996;109:659-63.

81. Mooe T, Rabben T, Wiklund U, et al. Sleep-disordered breathing in women: occurrence and association with coronary artery disease. Am J Med 1996;101:251-6.

82. Gami AS, Howard DE, Olson EJ, et al. Day-night pattern of sudden death in obstructive sleep apnea. N Engl J Med 2005:352:1206-14.

83. Mooe T, Franklin KA, Holmstrom K, et al. Sleep disordered breathing and coronary artery disease: long-term prognosis. Am J Respir Crit Care Med 2001:164:1910-13.

84. Peker Y, Carlson J, Hedner J. Increased incidence of coronary artery disease in sleep apnoea: a long-term follow-up. Eur Respir J 2006;28:596-602.

85. Hagenah GC, Gueven E, Andreas S. Influence of obstructive sleep apnoea in coronary artery disease: a 10-year follow-up. Respir Med 2006;100:180-2.

\section{Answers}

(A) FALSE (OSAHS requires a positive sleep study and daytime sleepiness to make a diagnosis).

(B) FALSE (At present OSAHS is only an independent risk factor for hypertension).

(C) TRUE (Potentially up to $8-10 \mathrm{~mm} \mathrm{Hg}$ in some hypertensive patients).

(D) FALSE (Treatment is only recommended in those who have coincidental OSAHS)

(E) TRUE (Important, as treatment of underlying sleep disorders can abolish the arrhythmia).

\section{FUNDING AVAILABLE FOR RESEARCH PROJECTS}

The Committee on Publication Ethics (COPE) has established a Grant Scheme to fund research in the field of publication ethics. The Scheme is designed to provide financial support to any member of COPE for a defined research project that is in the broad area of the organisation's interests, and specifically in the area of ethical standards and practice in biomedical publishing. The project should have a specific goal and be intended to form the kernel of a future publication.

A maximum sum of $£ 5000$ will be allocated to any one project, but applications for smaller sums are welcomed.

The terms and conditions of the Grant are as follows:

- At least one of the applicants must be a member of COPE.

- Calls for applications will be made twice a year with closing dates of 1 December and 1 June. An electronic version of the application form must be sent to the Administrator no later than $12 \mathrm{pm}$ (noon GMT) on the closing date for consideration by COPE Council.

- The application must contain a lay summary of the project, a definition of the question to be posed, sufficient methodological detail to allow assessment of the viability of the project, a clear timeline and a definition of the likely deliverables. A full justification for the sum requested must accompany the application.

- A report on the progress of the research should be presented within one year of the award and at the end of the project. The grant must be used within two years from the date of award, and balance sheets must be forwarded annually. These should be sent to the Administrator. Any remaining funds after two years must be returned.

- It is anticipated that the work stemming from the project will be presented at one of COPE's annual seminar meetings within 2-3 years of the award. Such data may also be published in peer-reviewed journals. Any publications or related presentations at meetings by the recipient emanating in part or whole from COPE's support should be duly acknowledged and copies sent to the Administrator.

Applications are reviewed by a COPE sub-committee. Applicants will be advised of a decision as soon as practicable after the deadline date.

An application form can be obtained by contacting Linda Gough, COPE administrator, at LGough@ bmj.com or 02073836602 . For more information on COPE, see http://www.publicationethics.org.uk/

The closing date for receipt of applications is 1 December 2007 or 1 June 2008. 